\title{
Images in Thorax
}

\section{Apical lung herniation}

\section{CASE HISTORY}

A 50-year-old man was referred to us complaining of a swelling in his neck while coughing. He had a 1-year history of a dry cough. He was an ex-smoker with a 10 pack-year history. Examination of his chest at rest was normal, without any cervical lymphadenopathy or signs of superior vena cava obstruction (figure 1A). Examination while coughing revealed a visible swelling on the right side of the neck (figure 1B). Chest radiograph was normal. CT of his chest was performed during inspiration and while performing a Valsalva manoeuvre, which showed an apical lung hernia at the right apex (figure 2A-C).

\section{DISCUSSION}

Apical lung herniation in adults is rare particularly in the absence of penetrating lung injury or chest wall disease. ${ }^{12}$ It is due to a defect in the suprapleural membrane (Sibson's fascia), and small incidental apical parietal pleural defects have been described which may be present prior to the development of a larger defect. ${ }^{3} 4$ Tearing of the fascia and spontaneous hernias have been described in players of wind instruments, weightlifters and those with a chronic cough, which may have occurred

\section{Learning points}

It is important to consider apical lung hernia in patients who complain of neck swelling and whose clinical examination and chest radiograph are normal.

- Diagnosis requires examination and CT imaging to be performed during a Valsalva manoeuvre. in our patient. ${ }^{2} 5$ The defect is usually large enough to prevent trapping and incarceration of the lung. ${ }^{3} 56$ Repair may be necessary in patients with incarceration, symptoms of local compression, for example, dysphagia from oesophageal compression, or for cosmetic purposes. ${ }^{7}$ The diagnosis can be easily missed both clinically and radiologically if examination is not made during a Valsalva manoeuvre.

\section{Harpreet Ranu, Mark Jackson}

Department of Respiratory Medicine, Brighton and Sussex University Hospitals NHS Trust, Haywards Heath, UK

Correspondence to Dr Harpreet Ranu, Department of Respiratory Medicine, Brighton and Sussex Hospitals NHS Trust, Princess Royal Hospital, Haywards Heath, Lewes Road, West Sussex RH16 4EX, UK; harpreet.ranu@bsuh.nhs.uk

\section{Competing interests None.}

Patient consent Obtained.

Provenance and peer review Not commissioned; externally peer reviewed.

Accepted 13 January 2011

Published Online First 20 April 2011

Thorax 2011;66:740. doi:10.1136/thx.2010.156240

\section{REFERENCES}

1. Li C, Miller WT. Air in the neck. Chest 1990;98:987-8.

2. Reinhart HA, Hermel MB. Herniation of the lung in the cervical region. Radiology 1951;57:204-7.

3. Bronsther B, Coryllos E, Epstein B, et al. Lung hernias in children. J Pediatr Surg 1968;3:544-50.

4. Galetta D, Serra M, Gossot D. Apical parietal pleural holes: what are they? Thorac Cardiovasc Surg 2010;58:237-8.

5. Bhalla $\mathbf{M}$, Leitman BS, Forcade $\mathrm{C}$, et al. Lung hernia: radiographic features. AJR Am J Roentgenol 1990;154:51-3

6. Grunebaum M, Griscom NT. Protrusion of the lung apex through Sibson's fascia in infancy. Thorax 1978;33:290-4.

7. McAdams HP, Gordon DS, White CS. Apical lung hernia: radiologic findings in six cases. AJR Am J Roentgenol 1996;167:927-30.

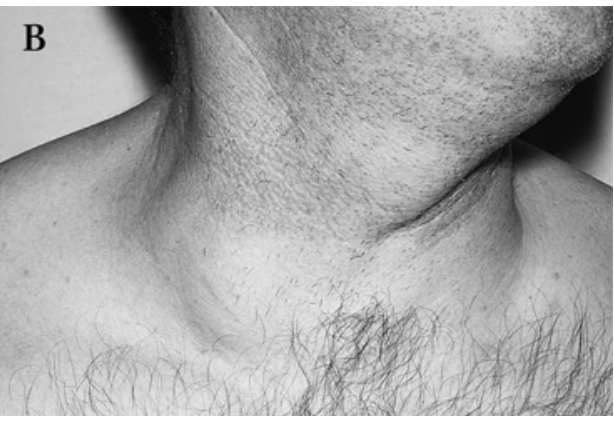

Figure 1 (A) Photograph of the patient at rest. (B) Photograph of the patient while coughing.
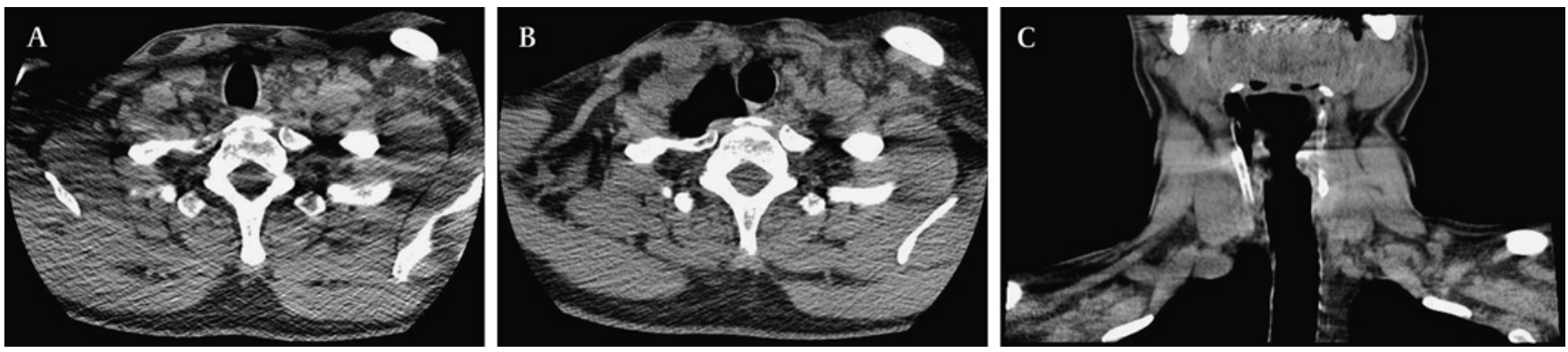

Figure 2 (A) CT scan of the thorax performed during inspiration shows no evidence of lung herniation. (B, C) CT scan of the thorax performed during a Valsalva manoeuvre shows herniated lung at the right apex. 